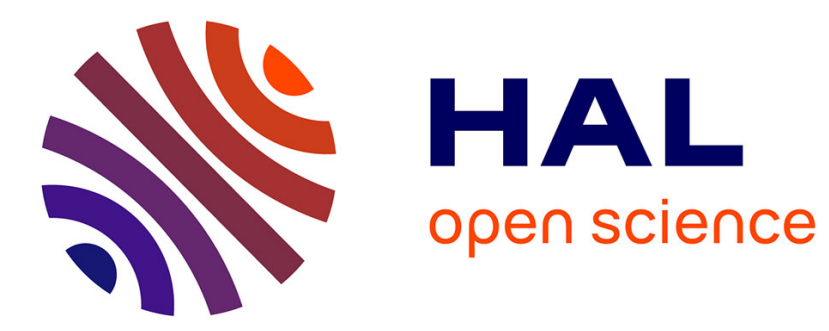

\title{
MATERIAL ANALYSIS AND SURFACE INTERACTION STUDIES USING LASER RESONANT MULTIPHOTON IONIZATION
}

T. Gibert, P. Pezé, B. Dubreuil, M. Barthe, J. Debrun

\section{- To cite this version:}

T. Gibert, P. Pezé, B. Dubreuil, M. Barthe, J. Debrun. MATERIAL ANALYSIS AND SURFACE INTERACTION STUDIES USING LASER RESONANT MULTIPHOTON IONIZATION. Journal de Physique IV Proceedings, 1991, 01 (C7), pp.C7-685-C7-688. 10.1051/jp4:19917184 jpa-00250863

HAL Id: jpa-00250863

https://hal.science/jpa-00250863

Submitted on 1 Jan 1991

HAL is a multi-disciplinary open access archive for the deposit and dissemination of scientific research documents, whether they are published or not. The documents may come from teaching and research institutions in France or abroad, or from public or private research centers.
L'archive ouverte pluridisciplinaire HAL, est destinée au dépôt et à la diffusion de documents scientifiques de niveau recherche, publiés ou non, émanant des établissements d'enseignement et de recherche français ou étrangers, des laboratoires publics ou privés. 


\title{
MATERIAL ANALYSIS AND SURFACE INTERACTION STUDIES USING LASER RESONANT MULTIPHOTON IONIZATION
}

\author{
T. GIBERT, P. PEZE, B. DUBREUIL, M.F. BARTHE* and J.L. DEBRUN* \\ GREMI, Université d'Orléans, CNRS, F-45067 Orléans cedex 2, France \\ "CERI, CNRS, rue de la Ferollerie, F-45071 Orléans cedex 2, France
}

\begin{abstract}
Resonance Ionization Spectroscopy (RIS) technique is an ultrasensitive method of detection of atoms and molecules. Application of RIS to material analysis requires an atomization step which is based in our set-up on ion beam sputtering. We present a review of the analytical studies we have performed demonstrating the very attractive potentialities of this method. RIS can be also used to study the surface sputtering process itself. Basic mechanisms of low energy laser desorption and vaporisation of metal samples have been investigated in this way.
\end{abstract}

\section{I - Introduction}

Resonant multiphoton ionization techniques using tunable pulsed dye lasers are widely used in the field of atomic and molecular spectroscopy /1/. By this method, known as "Resonance Ionlzation Spectroscopy" (RIS), atoms of a given element are selectively photoionized with a large probability. RIS is generally a two-step process in which atoms of the probed species are first excited in a well - defined quantum state by resonant absorption of $\mathrm{n}$ photons $(n=1,2)$ of wavelength $\lambda_{1}$ and then photoionized by absorption of $m$ supplementary photons $(m=1$ in most cases) of the same or of a different wavelength $(\mathrm{n}+\mathrm{m}$ photon process).

The first resonant step insures the elemental selectivity since only atoms in resonance are efficiently excited. This step saturates for $n=1$ with relatively low laser power density. During this excitation stage, every excited atom can be further photoionized. The probability of this second step is much smaller than for the resonant step. However, using commercial tunable pulsed UV laser (with frequency doubling and mixing) of a few GHz bandwidth, $(1+1)$ photoionization process can be saturated with only $10-100 \mathrm{MW} / \mathrm{cm}^{2}$, whereas $(2+1)$ photoionization process requires about $1 \mathrm{GW} / \mathrm{cm}^{2}$.

This is illustrated below (Fig. 1) in the case of $(1+1)$ photon ionization of $\mathrm{Mg}(\lambda=285.2 \mathrm{~nm})$ and $\mathrm{Fe}(\lambda=293.7 \mathrm{~nm}) / 2 /$ respectively and of the $(2+1)$ photon Ionization of $P(\lambda=299.3 \mathrm{~nm}) / 3 /$. These atoms were produced by ion sputtering of solid samples in a ultra-high vacuum chamber. 


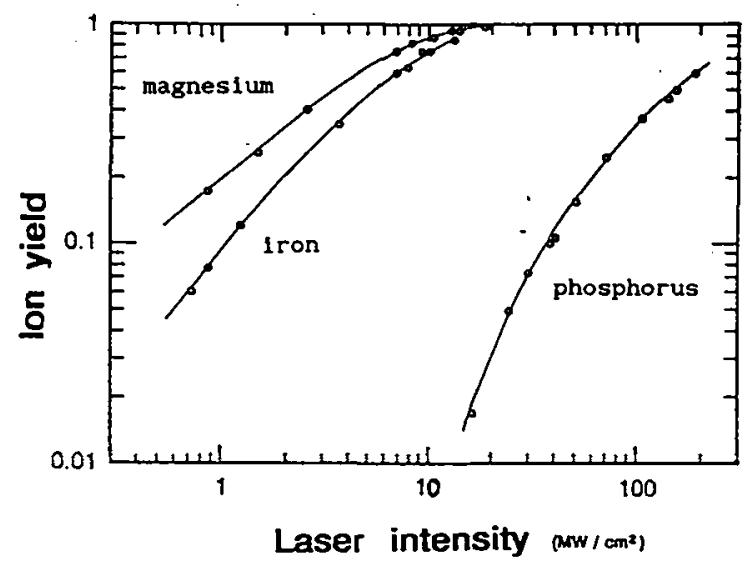

Fig. 1 - Resonant multiphoton ionization yield of $\mathrm{Mg}$, Fe and $\mathrm{P}$ atoms as a function of the laser power density.

II - Trace analysis in materials using RIS and ion beam sputtering

Good selectivity, near unity photolonization yleld make RIS very attractive for elemental analysis. Trace analysis in materials requires an atomisation step before RIS is applicable. The aim of this step is the liberation of neutral atoms representative of the atomic composition of the sample. Among different atomization methods, ion beam sputtering appears particlarly well adapted, allowing lateral resolution in the micrometer range, depth profiling and precise control of the material consumption. Furthermore, in the case of metals and semiconductors most of the sputtered particles are neutral atoms (non reactive sputtering). With insulators or with reactive sputtering the amount of secondary lons can reach a few tens of percent.

In our laboratory, coupling of RIS with ion beam sputtering technique (SIRIS : sputtered initiated RIS /4/) is developed around a U.H.V. chamber, a $\mathrm{Ar}^{+}$duoplasmatron ion gun, a quadrupolar mass - spectrometer and a Nd : Yag laser pumped dye laser with doubling and mixing.

Due to the pulsed operation of the probe laser beam, two modes of analyses are possible. In c.w. sputtering, the lon beam continuously sputters the surface whereas the laser beam perlodically $(10 \mathrm{~Hz})$ probes the concentration of a given species at increasing depths in the material (depth profiling). In pulsed operation, the ion beam sputters the surface during a short time $(1-10 \mu \mathrm{s})$, producing a cloud of atoms propagating perpendicularly above the surface. The probe laser is fired at the time when the expending packet crosses the interaction zone. The sputtering duration is adjusted for the best overlap between the atom cloud and the laser beam. In this mode, the material consumption is very small.

are :

Advantages of SIRIS over other surface analytical methods (SIMS)

- elimination of matrix effects in metal and semiconductors /5/

- linearity and quantitativity /5/

- high sensitivity, large useful yield : 1 ppm detection on a single laser shot for a $(1+1)$ photon process with the sputtering of less than a monolayer $/ 2 /, 100 \mathrm{ppm}$ for a $(2+1)$ photon process $/ 3 /$.

- removal of mass-interferences $/ 3 /$.

- pulsed operation for analysis of insulating materialsi minimizes 
charging effects and field effects on the surface).

For example, Fig. 2 shows the recording in counting mode $(2000$ laser shots) of the $\mathrm{Fe}^{+}$photoion pulse obtained from a $13 \mathrm{ppm}$ Fe doped $\mathrm{SlO}_{2}$ sample. In this experience, pulsed sputtering conditions were use to overcome the problem of charging effects $/ 6 /$. Note also the efficient isicrimination between ${ }^{56} \mathrm{Fe}$ photoions and ${ }^{28} \mathrm{Siz}$ secondary ions - a typical mass interference problem.

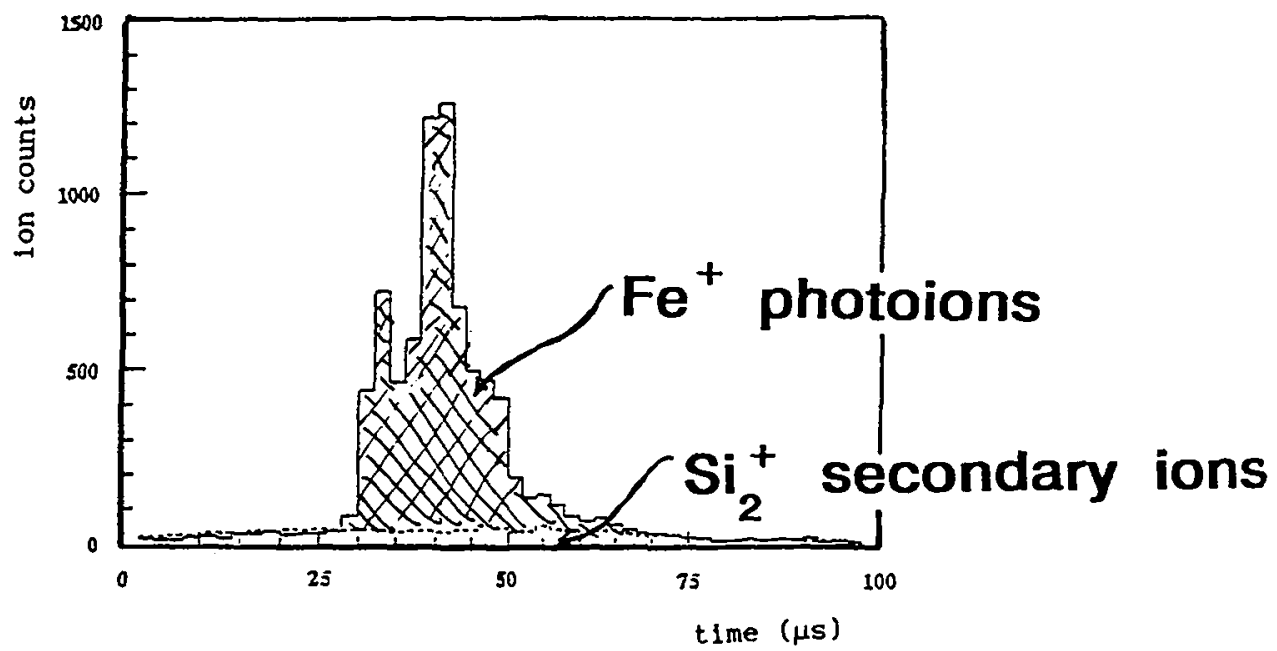

photoion pulse. 2 Detection of $13 \mathrm{ppm}$ of $\mathrm{Fe}$ in $\mathrm{SiO} 2$ : recording of the $\mathrm{Fe}$ conditions. Material consumption : less than a monolayer on a $300 \mu \mathrm{m}$ diameter spot.

III - RIS studies of ion or laser beam interaction with surfaces

Several surface characterization methods as well as materlal processing techniques (film deposition, etching, surface treatment ...) are based on the interaction of energetic beams of particles or laser beams with materials. One can get an insight into the physics of the interaction process by analysing the characteristics of the particles which are emitted by or scattered from the surface. For example, using RIS, Winograd et al. /7/ made an energy and angle resolved analysis of atoms sputtered from a surface by an incident $\mathrm{Ar}^{+}$ion beam and compared the results with sophisticated models describing the collision processes between incident ions and atoms of the material.

In the case of film deposition using elther ion beam or laser beam sputtering of a composite material, real - time monitoring and precise control of the process needs knowledge of the space and energy distributions of the sputtered products as well as their chemical composition as they impinge on the substrate. Since most of these processes are performed under vacuum or very low pressure conditions, RIS is relatively well adapted for this purpose. Using the SIRIS experimental set-up, we have measured the relative concentrations of oxygen and copper atoms which are emitted during the $\mathrm{Ar}^{+}$ion beam sputtering of a YBaCuO superconducting target. A very low emission of oxygen atoms was detected in agreement with other observations $/ 8 /$, indicating that most of the oxygen of the material is sputtered as metal oxides.

Surface sputtering induced by an incident laser beam (ablation, vaporization) is also becoming increasingly important as technologies are 
developed which utilize this process. Basic mechanisms of low energy laser desorption and vaporization are currently under study in several groups 19 , 10/. We have investigated using RIMS, the sputtering of iron and alloys surfaces Irradiated by the focused beam of a $\mathrm{N} 2$ laser in the $20-350 \mathrm{~mJ} / \mathrm{cm}^{2}$ fluence range.

Delaying the RIS probe laser beam with respect to the ablating laser pulse, the time-of-flight (TOF) distribution of Fe atoms emitted by the irradiated surface was recorded as a function of the incident laser energy.Fig. 3 shows such TOF distribution obtalned for a $120 \mathrm{~mJ} / \mathrm{cm}^{2}$ fluence. These distributions are compared to theoretical models : pure thermal emission (half-space Maxwell distribution) or hydrodynamical model (Maxwell distribution with a finite center of mass velocity). In the laser fluence range investigated, it appears that pure thermal emission model fits rather well our experimental results as the density of emitted atoms is too low to establish a Knudsen layer on the surface. The kinetic temperature of the atomic beam is directly deduced from the fits.

Atomic excitation temperature is determined from RIS probing of the population distribution in the fine structure levels of the Fe ground state. The results are reported in Fig. 4 as a function of the laser fluence and are compared with the kinetic temperature. The reasonable agreement which is observed, corroborates the pure thermal model. It is interesting to note that in this case the excitation temperature probed in the atomic beam reflects rather well the thermal state of the atoms as they leave the surface. Indeed one observes in Fig. 4 an increase of the excitation temperature from the ambient at the threshold to the melting and boiling temperature values at the highest laser energies.

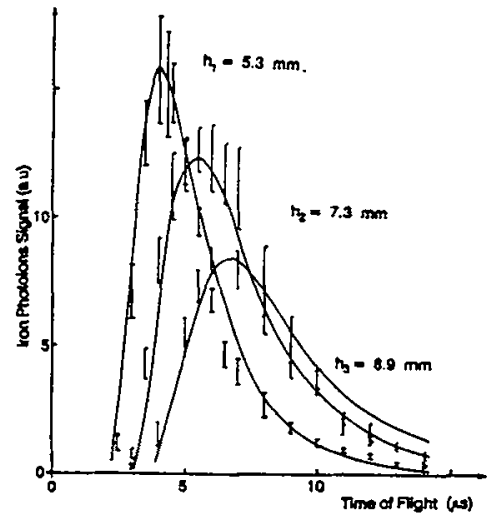

Fig. 3 - T.O.F. distribution of $\mathrm{Fe}$ atoms emitted by a alloy sample irradiated by the beam of a $\mathrm{N}_{2}$ laser

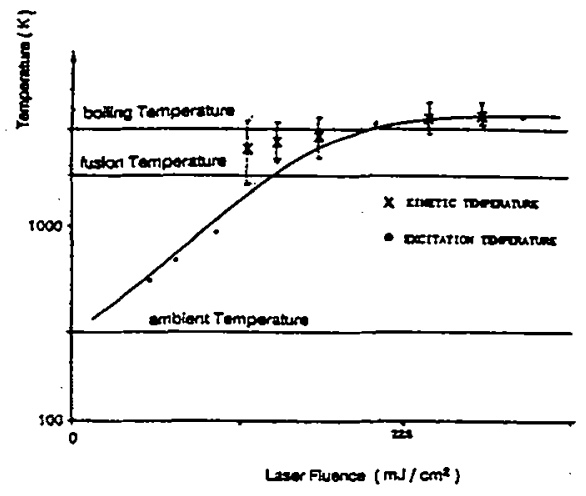

Fig. 4 - Excitation and kinetic temperatures of the evaporated Fe atoms

\section{References :}

/1/ G.S. Hurst et al, Rev. Mod. Phys. 51 (1979) 767

V.S. Letokhov, "Laser photoionization spectroscopy" (Acad. Press 1987)

$12 / 0$. Gobert et al., submitted to J. Appl. Phys. (1991)

$/ 3 /$ O. Gobert et al., Phys. Rev. A 41 (1990) 6225

/4/ J.E. Parks et al., Thin Solid Films 108 (1983) 69

/5/ P. Gelin et al.. N.I.M. B 40/41 (1989) 290

/6/ M.F. Barthe et al., N.I.M. B 56/57 (1991) 893

/7/ N. Winograd et al., Surf. Science 176 (1986) L817

/8/ C.B. Fleddermann, J. Appl. Phys. 67 (1990) 3818

/9/ H.F. Arlinghaus et al., J. Vac. Sci. Technol. A7 (1989) 1766

/10/ R. Kelly, J. Chem. Phys. 92 (1990) 5047 